\title{
Expression and role of EGFR, cyclin D1 and KRAS in laryngocarcinoma tissues
}

\author{
XINSHENG LIN ${ }^{1}$, GUOFENG WEN ${ }^{1}$, SHUANGLE WANG ${ }^{1}$, HANGUI LU ${ }^{1}$, CHUANGWEI LI $^{1}$ and XIN WANG ${ }^{2}$ \\ ${ }^{1}$ Department of Otolaryngology-Head and Neck Surgery, Shantou Central Hospital, \\ Shantou, Guangdong 515031; ${ }^{2}$ Department of Otolaryngology-Head and Neck Surgery, \\ The First Hospital of Jilin University, Changchun, Jilin 130000, P.R. China
}

Received June 6, 2018; Accepted October 26, 2018

DOI: $10.3892 /$ etm.2018.7027

\begin{abstract}
Epidermal growth factor receptor (EGFR), cyclin D1 and KRAS proto-oncogene, GTPase (KRAS) genes serve roles in the occurrence and development of tumors. The aim of the current study was to investigate the expression levels of EGFR, cyclin D1 and KRAS in laryngocarcinoma tissues and their association with clinical features. In addition, correlation between the expression levels of EGFR, cyclin D1 and KRAS was analyzed in laryngocarcinoma tissues. The expression levels of EGFR, cyclin D1 and KRAS in 46 patients with laryngocarcinoma and 20 patients with vocal cord polyps as the control group were determined using Super Vision immunohistochemical staining assay kits. The differences in clinical and pathological parameters between groups were statistically analyzed using SPSS software version 16.0. The expression rates of EGFR, cyclin D1 and KRAS were 71.7, 52.2 and $39.1 \%$, respectively in laryngocarcinoma tissues, and 10.0, 5.0 and $10.0 \%$, respectively in vocal cord polyps. There was a positive correlation between the expression levels of EGFR, cyclin D1 and KRAS. The expression of these genes was also closely associated with the clinical stage, treatment response and prognosis of patients with laryngocarcinoma. Multivariate analysis of prognosis using the Cox regression model indicated that EGFR expression in laryngocarcinoma tissues and the clinical stage of patients with laryngocarcinoma were closely associated with patient prognosis. The results of the current study indicated that EGFR, cyclin D1 and KRAS were synergistically involved in the occurrence and development of laryngocarcinoma, directly affecting the prognosis of patients. Additionally, high expression of EGFR, cyclin D1 and KRAS facilitated the invasion and metastasis of laryngocarcinoma cells. The expression of EGFR in laryngocarcinoma tissues
\end{abstract}

Correspondence to: Professor Xin Wang, Department of Otolaryngology-Head and Neck Surgery, The First Hospital of Jilin University, 71 Xinmin Road, Changchun, Jilin 130000, P.R. China E-mail: docxinwang@126.com

Key words: laryngocarcinoma, epidermal growth factor receptor, cyclin D1, KRAS proto-oncogene, GTPase, prognosis and clinical stage were two independent risk factors affecting the prognosis of patients.

\section{Introduction}

Laryngocarcinoma is one of the most common malignant tumors in otolaryngology requiring head and neck surgery, accounting for $\sim 1-5 \%$ of all types of cancer and $7.9-35 \%$ of otolaryngologic malignancies (1). With increasing incidence, laryngocarcinoma ranks third in otolaryngologic malignancies and is a squamous cell carcinoma in $90 \%$ of cases (2).

The mechanism underlying the occurrence of laryngocarcinoma remains to be elucidated. Progress in gene research indicated that certain genes serve important roles in the occurrence and development of laryngocarcinoma. Among these, epidermal growth factor receptor (EGFR) (3), cyclin D1 (4) and KRAS proto-oncogene, GTPase (KRAS) (5) attracted attention in the field of head and neck cancer research due to their strong association with tumorigenesis, invasion, lymph node metastasis, recurrence and prognosis. Furthermore, EGFR and cyclin D1 are recognized as regulators of cancer cell proliferation, migration and patient survival in laryngocarcinoma (6-8). In addition, EGFR expression is markedly increased during the progression from laryngeal dysplasia to carcinoma (9). In addition, the Ras signaling pathway is involved in the formation of tumor microenvironment and is closely associated with tumorigenesis and progression $(7,10)$. However, correlation between EGFR, cyclin D1 and KRAS is rarely reported in laryngocarcinoma, and whether the three genes serve a synergistic role in the occurrence and development of laryngocarcinoma requires further investigation. To the best of our knowledge, the expression and synergy of EGFR, cyclin D1 and KRAS in patients with laryngocarcinoma have not been previously reported. Studies on the association between the expression of EGFR, cyclin D1 and KRAS in laryngocarcinoma and patient clinical features, and the correlation between the expression levels of these three genes, may elucidate the biological features of laryngocarcinoma.

In the current study, the expression levels of EGFR, cyclin D1 and KRAS were investigated to determine the association between their expression in laryngocarcinoma tissues and clinical features of the disease using immunohistochemical staining and statistical analysis. In addition, the 
current study aimed to elucidate whether there is a synergistic association among these genes and whether their expression levels are associated with prognosis. The results of the present may aid in evaluating the severity of laryngocarcinoma and selecting the most appropriate treatment option and provides a theoretical basis for gene targeted drug discovery and therapy.

\section{Materials and methods}

General patient information. Paraffin-embedded tissue samples from 46 patients with primary laryngeal squamous cell carcinoma (LSCC) and 20 patients diagnosed with vocal cord polyps (VCPs) were collected as the study group and control group, respectively, at the Shantou Central Hospital (Shantou, China) from 2005 to 2011. All cases had $>5$ years of follow-up results. Among the 46 cases of LSCC (Table I), 45 (97.83\%) were male and $1(2.17 \%)$ was female; the age of onset was 43-70 years old, with 9 cases $(19.57 \%)$ at the age $<50,37$ cases $(80.43 \%) \geq 50$, and the median age was 60 years old. Prior to treatment, the cancer stage was determined using electronic laryngoscopy, B-mode ultrasound, X-ray analysis, computed tomography, magnetic resonance imaging, pathology and classified using the Union for International Cancer Control Tumor Node Metastasis (TNM) Classification System for laryngocarcinoma, the 8th Edition (2017) (11). A total of 19 cases were stage T1-T2 (41.30\%), 22 cases (47.83\%) stage T3 and 5 cases $(10.87 \%)$ stage T4. Prior to treatment, there were 43 cases (93.48\%) free of cervical lymph node metastasis (N0), and 3 cases with cervical lymph node metastasis $(6.52 \%)$, all of which were stage N1. Following treatment, there were 28 cases $(60.87 \%)$ with recurrent disease or metastasis. The 46 patients with LSCC were treated with surgery, including cordectomy, partial laryngectomy, total laryngectomy and cervical lymph node dissection. Stage T4 patients and certain patients with stage T3 were treated with Cobalt-60 radiotherapy and/or 5-fluorouracil and cisplatin chemotherapy as adjuvant therapy.

Immunohistochemical detection. A total of 46 samples of laryngocarcinoma tissues and 20 control samples of vocal cord polyp tissues were collected. Immunohistochemical (IHC) staining was performed using a Super Vision IHC kit (cat. no. SV0002; Wuhan Boster Biological Technology, Ltd., Wuhan, China). The samples were fixed with $4 \%$ paraformaldehyde at $4^{\circ} \mathrm{C}$ for $\sim 24 \mathrm{~h}$, dehydrated through a graded series of ethanol, washed with xylene and embedded in paraffin. Serial $5 \mu \mathrm{m}$ sections were then cut, conventionally dewaxed and rehydratedin xylene and a descending alcohol series, and rinsed in deionized water. Endogenous peroxidase was quenched by $3 \%$ hydrogen peroxide in deionized water. Antigen retrieval was performed by incubating the slides in pH 6.0 citrate buffer ( $0.01 \mathrm{M}$ sodium citrate-citric acid buffer; EDTA buffer for cyclin D1) at $98^{\circ} \mathrm{C}$ for $10 \mathrm{~min}$, followed by incubation with $10 \%$ goat serum blocking solution (cat. no. AR0009; Wuhan Boster Biological Technology, Ltd.) for $20 \mathrm{~min}$ at room temperature and primary antibodies against EGFR (1:50; cat. no. ZA-0505; OriGene Technologies, Inc., Rockville, MD, USA), CyclinD1 (1:50; cat. no. RMA-0541; Fuzhou Maixin Biotech Co., Ltd., Fuzhou, China) and K-ras (1:50; cat. no. bs-1033R; Bioss Antibodies, Inc., Woburn, MA, USA) at $4^{\circ} \mathrm{C}$ overnight. After two washes with PBS, polymeric
Table I. Baseline status of patients with LSCC.

Characteristic

Patients with LSCC (n=46)

Age $($ mean $\pm \mathrm{SD}$, years $)$
$<50$
$\geq 50$
Sex
Male

$58.0 \pm 9.5$

$9(19.57 \%)$

$37(80.43 \%)$

Female

$45(97.83 \%)$

$1(2.17 \%)$

BMI (mean $\left.\pm \mathrm{SD}, \mathrm{kg} / \mathrm{m}^{2}\right)$

$23.34 \pm 2.33$

Smoking status

Yes

$24(52.17 \%)$

No

$22(47.83 \%)$

Drinking status

Yes

$20(43.48 \%)$

No

$26(56.42 \%)$

Years since diagnosis, mean

0.62

Clinical stage

$\begin{array}{lr}\text { I-II } & 19(41.30 \%) \\ \text { III } & 22(47.83 \%) \\ \text { IV } & 5(10.87 \%) \\ \text { Metastasis status before treatment } & \\ \text { Yes } & 3(6.52 \%) \\ \text { No } & 43(93.48 \%)\end{array}$

SD, standard deviation; LSCC, laryngeal squamous cell carcinoma; BMI, body mass index.

horseradish peroxidase-conjugated anti-rabbit immunoglobulin G secondary antibody (provided in the Super Vision IHC kit) was incubated with the slides for $30 \mathrm{~min}$ in a $37^{\circ} \mathrm{C}$. Following 3,3'-diaminobenzidine staining, sections were counterstained with hematoxylin for $2 \mathrm{~min}$ at room temperature, dehydrated and attached to coverslips.

Results assessment. Brown and tan color indicated positive EGFR, cyclin D1 and KRAS staining. Yellow staining in the nucleus, cytoplasm or cell membrane was considered a positive signal. For the semiquantitative scoring analysis, each section was observed in five randomly selected high-power fields (x200) with a light microscope (Axioplan 2; Carl Zeiss AG, Oberkochen, Germany). The total number of cells and the number of positive cells were counted in each field of view, the percentage of positive cells was calculated and averaged, and the percentages were divided into four grades and recorded as $0,1,2$, or 3 points. The following scoring system was used: i) $0,<25 \%$ positive cells; ii) $1,25-49 \%$ positive cells; iii) 2 , $50-74 \%$ positive cells; and iv) $3, \geq 75 \%$ positive cells. The following scoring system was used to for staining intensity: i) 0 , no color development; ii) 1 , light yellow; iii) 2 , orange; iv) 3 tan. The final scores were obtained by adding the two score types, which were subsequently divided by 2 . Negative (-) result was defined as 0 points; 0.5 or 1.0 indicated a weakly positive $(+)$ result; 1.5 or 2.0 indicated a positive $(++)$ result; and 2.5 or 3.0 indicated a strong positive $(+++)$ result. Negative 


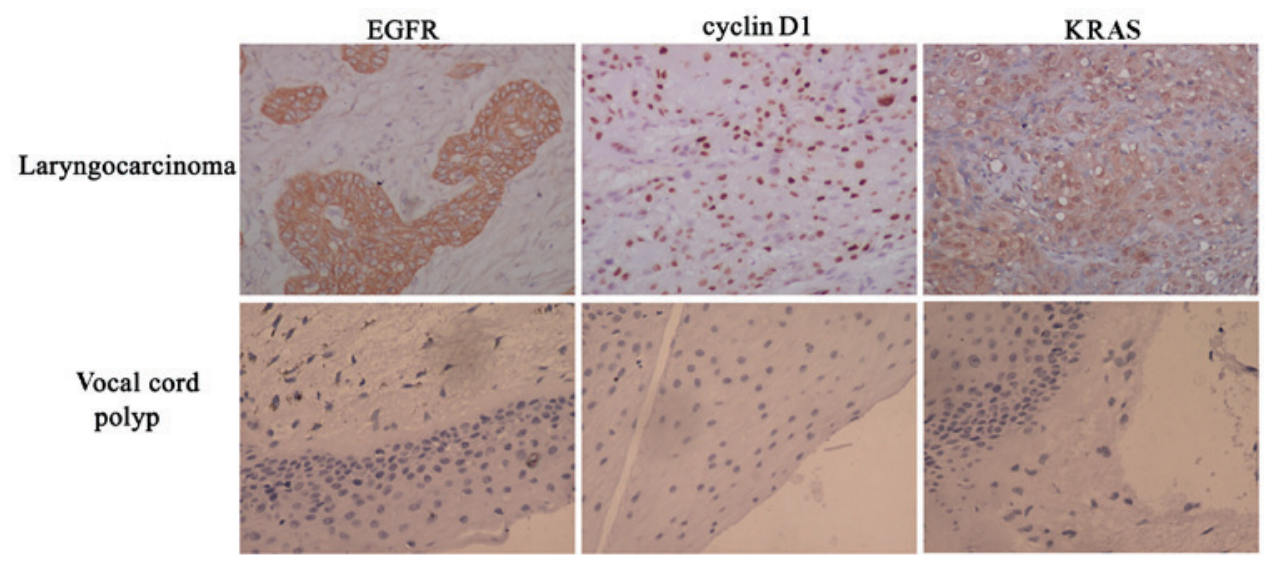

Figure 1. Immunohistochemical analysis of EGFR, cyclin D1 and KRAS expression in laryngocarcinoma tissues and vocal cord polyp tissues (magnification, x200). EGFR, epidermal growth factor receptor; KRAS, KRAS proto-oncogene, GTPase.

and weakly positive expression was defined as low expression; positive and strongly positive expression was defined as high expression.

Statistical analyses. The experimental data were analyzed using SPSS software (version 16.0; SPSS, Inc., Chicago, IL, USA). A $\chi^{2}$ test was used to analyze the association between gene expression and sex, age, clinical stage of patients with laryngocarcinoma, and metastasis status following treatment. Spearman's correlation was used to analyze the association between gene expression levels. The mean survival time and survival rate of each group were calculated using the Kaplan-Meier method for univariate analysis of prognostic factors for overall survival. Log-rank test was used to compare the survival rate of each group, and multivariate analysis of prognostic factors was performed using the Cox proportional hazards model. $\mathrm{P}<0.05$ was considered to indicate a statistically significant difference.

\section{Results}

EGFR, cyclin DI and KRAS staining results and their association with clinical features. EGFR was mainly located in the membrane and cytoplasm of laryngocarcinoma cells, as indicated by brown staining. Cyclin D1 was primarily located in the nucleus, as indicated by tan staining, and KRAS was mainly observed as tan or brown staining located in the cytoplasm and nucleus. The expression of EGFR, cyclin D1 and KRAS in vocal cord polyp tissues were very low (Fig. 1).

The expression rates of EGFR, cyclin D1 and KRAS in laryngocarcinoma tissues were 71.7, 52.2 and $39.1 \%$, respectively, while those in vocal cord polyps were only 10.0, 5.0 and $10.0 \%$, respectively. The differences in EGFR, cyclin D1 and KRAS expression levels between the laryngocarcinoma tissues and the vocal cord polyp tissues were statistically significant, $(\mathrm{P}<0.001, \mathrm{P}<0.001$ and $\mathrm{P}=0.021$, respectively; Tables II-IV $)$. The expression levels of EGFR, cyclin D1 and KRAS were significantly associated with the clinical stage and treatment response $(\mathrm{P}<0.05)$. There was no association between the expression of EGFR, cyclin D1 and KRAS and the age of patients, and no significance in the different expression levels between the laryngocarcinoma and vocal cord polyp groups $(\mathrm{P}>0.05)$.
Correlation between EGFR, cyclin DI and KRAS expression in laryngocarcinoma tissues. As presented in Tables V-VII, positive co-expression of EGFR and cyclin D1, EGFR and KRAS, and cyclin D1 and KRAS in laryngocarcinoma tissues was identified in 33 (33/46), 34 (34/46) and 33 (33/46) of the cases, respectively. Spearman's correlation analysis indicated that the expression of EGFR was positively correlated with the expression of cyclin D1 $(r=0.356 ; \mathrm{P}=0.015)$ and KRAS $(\mathrm{r}=0.479 ; \mathrm{P}=0.001)$ and the expression of cyclin $\mathrm{D} 1$ was positively correlated with the expression of KRAS $(r=0.604$; $\mathrm{P}<0.001)$ in laryngocarcinoma tissues.

Association between the expression levels of EGFR, cyclin DI and KRAS in laryngocarcinoma tissues and patient prognosis. Survival analysis of patients with laryngocarcinoma with low and high EGFR, cyclin D1 and KRAS expression indicated that the prognosis of patients was associated with the expression levels of these proteins ( $\log$ rank value, 4.261, 6.219 and 5.916, respectively; Tables VIII, IX and Fig. 2; $\mathrm{P}=0.039, \mathrm{P}=0.013$ and $\mathrm{P}=0.015$, respectively; Tables VIII, IX and Fig. 2).

Association between the clinical features in laryngocarcinoma and prognosis. Survival analysis of patients with laryngocarcinoma indicated that the prognosis was associated with the treatment response and clinical stage (log rank value, 53.047 and 45.233; all $\mathrm{P}<0.05)$. The prognosis of patients with laryngocarcinoma was not significantly associated with age, smoking and drinking (log rank value, 0.166, 0.168 and 0.212, respectively; Table IX and Fig. 2; $\mathrm{P}=0.684, \mathrm{P}=0.682$ and $\mathrm{P}=0.645$, respectively; Table IX and Fig. 2).

Multivariate analysis of prognosis using the Cox proportional hazards model. A total of eight variables, including age, clinical stage, recurrence or metastasis after treatment, smoking and drinking status, and EGFR, cyclin D1 and KRAS expression levels, were selected for the Cox regression model for multivariate analysis (Table $\mathrm{X}$ ). The results indicated that treatment response was significantly associated with patient prognosis $(\mathrm{P}=0.001)$. Furthermore, clinical stage was significantly associated with patient prognosis, with $\mathrm{P}=0.001$ for TNM I-II, $\mathrm{P}=0.017$ for TNM III and $\mathrm{P}<0.001$ for TNM IV. 
Table II. Association between EGFR expression and clinical features.

\begin{tabular}{|c|c|c|c|c|c|c|}
\hline \multirow[b]{2}{*}{ Clinical parameter } & \multirow[b]{2}{*}{ Total } & \multicolumn{2}{|c|}{ EGFR } & \multirow[b]{2}{*}{ High expression rate, $\%$} & \multirow[b]{2}{*}{$\chi^{2}$} & \multirow[b]{2}{*}{ P-value } \\
\hline & & Low & High & & & \\
\hline \multicolumn{7}{|l|}{ Tissue source } \\
\hline Polyp of vocal cord & 20 & 18 & 2 & 10 & 21.332 & $<0.001$ \\
\hline Laryngocarcinoma & 46 & 13 & 33 & 71.7 & & \\
\hline \multicolumn{7}{|l|}{ Age group } \\
\hline$<50$ & 9 & 1 & 8 & 88.9 & 1.623 & 0.203 \\
\hline$\geq 50$ & 37 & 12 & 25 & 67.6 & & \\
\hline \multicolumn{7}{|l|}{ TNM classification } \\
\hline I-II & 19 & 8 & 11 & 57.9 & 63.773 & $<0.001$ \\
\hline III & 22 & 5 & 17 & 77.3 & & \\
\hline IV & 5 & 0 & 5 & 100.0 & & \\
\hline \multicolumn{7}{|c|}{ Recurrence or metastasis after treatment } \\
\hline No & 28 & 11 & 17 & 60.7 & 4.290 & 0.049 \\
\hline Yes & 18 & 2 & 16 & 88.9 & & \\
\hline
\end{tabular}

EGFR, epidermal growth factor receptor; TNM, tumor, node metastasis.

Table III. Association between cyclin D1 expression and clinical features.

\begin{tabular}{|c|c|c|c|c|c|c|}
\hline \multirow[b]{2}{*}{ Clinical parameter } & \multirow[b]{2}{*}{ Total } & \multicolumn{2}{|c|}{ Cyclin D1 } & \multirow[b]{2}{*}{ High expression rate, $\%$} & \multirow[b]{2}{*}{$\chi^{2}$} & \multirow[b]{2}{*}{ P-value } \\
\hline & & Low & High & & & \\
\hline \multicolumn{7}{|l|}{ Tissue source } \\
\hline Polyp of vocal cord & 20 & 19 & 1 & 5.0 & 13.183 & $<0.001$ \\
\hline Laryngocarcinoma & 46 & 22 & 24 & 52.2 & & \\
\hline \multicolumn{7}{|l|}{ Age group } \\
\hline$<50$ & 9 & 4 & 5 & 55.6 & 0.008 & 0.999 \\
\hline$\geq 50$ & 37 & 18 & 19 & 51.4 & & \\
\hline \multicolumn{7}{|l|}{ TNM classification } \\
\hline I-II & 19 & 14 & 5 & 26.3 & 8.902 & 0.012 \\
\hline III & 22 & 7 & 15 & 68.2 & & \\
\hline IV & 5 & 1 & 4 & 80.0 & & \\
\hline \multicolumn{7}{|c|}{ Recurrence or metastasis after treatment } \\
\hline No & 28 & 18 & 10 & 35.7 & 6.286 & 0.027 \\
\hline Yes & 18 & 4 & 14 & 77.8 & & \\
\hline
\end{tabular}

TNM, tumor, node metastasis.

\section{Discussion}

The results of the current study indicated that the expression of EGFR, cyclin D1 and KRAS in laryngocarcinoma tissues was significantly increased compared with the vocal cord polyps, and the expression of EGFR, cyclin D1 and KRAS was closely associated with the clinical stage, treatment response and prognosis. The expression levels of EGFR, cyclin D1 and KRAS in laryngocarcinoma tissues were positively correlated, indicating that these proteins may be involved in the occurrence and development of laryngocarcinoma. Furthermore, it may be hypothesized that increased expression of EGFR, cyclin D1 and KRAS promote invasion and metastasis of laryngocarcinoma cells and act in synergy to promote the occurrence and development of laryngocarcinoma. In the current study, the clinical stage, recurrence or metastasis status after treatment, and the expression levels of EGFR, cyclin D1 and KRAS were the factors affecting the prognosis of patients. Treatment response and clinical stage were two independent risk factors affecting the prognosis of patients. 
Table IV. Association between KRAS expression and clinical features.

\begin{tabular}{|c|c|c|c|c|c|c|}
\hline \multirow[b]{2}{*}{ Clinical parameter } & \multirow[b]{2}{*}{ Total } & \multicolumn{2}{|c|}{ KRAS } & \multirow[b]{2}{*}{ High expression rate, $\%$} & \multirow[b]{2}{*}{$\chi^{2}$} & \multirow[b]{2}{*}{ P-value } \\
\hline & & Low & High & & & \\
\hline \multicolumn{7}{|l|}{ Tissue source } \\
\hline Polyp of vocal cord & 20 & 18 & 2 & 10.0 & \multirow[t]{2}{*}{5.601} & \multirow[t]{2}{*}{0.021} \\
\hline Laryngocarcinoma & 46 & 28 & 18 & 39.1 & & \\
\hline \multicolumn{7}{|l|}{ Age group } \\
\hline$<50$ & 9 & 6 & 3 & 22.2 & \multirow[t]{2}{*}{0.158} & \multirow[t]{2}{*}{0.999} \\
\hline$\geq 50$ & 37 & 22 & 15 & 40.5 & & \\
\hline \multicolumn{7}{|l|}{ TNM classification } \\
\hline I-II & 19 & 16 & 3 & 15.8 & \multirow[t]{3}{*}{8.943} & \multirow[t]{3}{*}{0.011} \\
\hline III & 22 & 11 & 11 & 50.0 & & \\
\hline IV & 5 & 1 & 4 & 80.0 & & \\
\hline \multicolumn{7}{|c|}{ Recurrence or metastasis after treatment } \\
\hline No & 28 & 20 & 8 & 28.6 & \multirow[t]{2}{*}{4.041} & \multirow[t]{2}{*}{0.044} \\
\hline Yes & 18 & 8 & 11 & 61.1 & & \\
\hline
\end{tabular}

TNM, tumor, node metastasis; KRAS, KRAS proto-oncogene, GTPase.

Table V. Correlation between EGFR and cyclin D1 in laryngocarcinoma tissues.

\begin{tabular}{lrrrrr}
\hline & \multicolumn{5}{c}{ Cyclin D1 } \\
\cline { 2 - 5 } & - & + & ++ & +++ & Total \\
\hline EGFR & 3 & 2 & 2 & 0 & 7 \\
- & 2 & 2 & 1 & 1 & 6 \\
+ & 3 & 4 & 9 & 0 & 16 \\
++ & 1 & 5 & 7 & 4 & 17 \\
+++ & 9 & 13 & 19 & 5 & 46 \\
Total & 9 & & & & \\
\hline
\end{tabular}

$\mathrm{r}=0.356 ; \mathrm{P}=0.015$. EGFR, epidermal growth factor receptor.

Table VI. Correlation between EGFR and KRAS in laryngocarcinoma tissues.

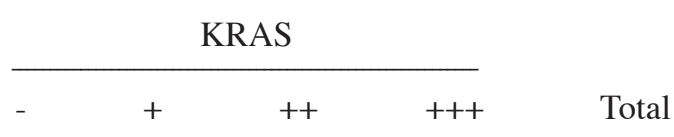

\begin{tabular}{lrrrrr}
\hline EGFR & & & & & \\
- & 4 & 2 & 1 & 0 & 7 \\
+ & 3 & 3 & 0 & 0 & 6 \\
++ & 2 & 5 & 9 & 0 & 16 \\
+++ & 0 & 9 & 5 & 3 & 17 \\
Total & 9 & 19 & 15 & 3 & 46 \\
\hline
\end{tabular}

$\mathrm{r}=0.479 ; \mathrm{P}=0.001$. EGFR, epidermal growth factor receptor; KRAS, KRAS proto-oncogene, GTPase.
Table VII. Correlation between cyclin D1 and KRAS in laryngocarcinoma tissues.

\begin{tabular}{lrrrrr}
\hline & \multicolumn{5}{c}{ KRAS } \\
\cline { 2 - 4 } & - & + & ++ & +++ & Total \\
\cline { 2 - 5 } & & & & & \\
Cyclin D1 & 5 & 3 & 1 & 0 & 9 \\
- & 3 & 9 & 0 & 1 & 13 \\
+ & 1 & 6 & 11 & 1 & 19 \\
++ & 0 & 1 & 3 & 1 & 5 \\
+++ & 9 & 19 & 15 & 3 & 46 \\
Total & 9 & & & &
\end{tabular}

$\mathrm{r}=0.604 ; \mathrm{P}<0.001$. KRAS, KRAS proto-oncogene, GTPase.

EGFR is a ligand-mediated multifunctional transmembrane glycoprotein that activates tyrosine kinase and is present on the cell membrane of the majority of tissue types with the exception of the hematopoietic system in the human body (12). EGFR binds EGF with high affinity and this interaction exhibits time and temperature dependence, saturation and reversibility (12). Following activation of the EGFR tyrosine kinase, cascade amplification of signal transduction is achieved through the RAS-RAF-MEK-MAPK, PI3K-PKC-IKK, and JAK-STAT pathways, which deliver extracellular mitotic signals into the cell, thus regulating normal cell growth, differentiation and cell cycle and promoting damage repair (13). EGFR is highly expressed in a number of solid tumors and is closely associated to tumor progression, apoptosis, angiogenesis and metastasis (14). In vitro and in vivo experiments have demonstrated that EGFR is an important anticancer target in the development and progression of laryngocarcinoma (15). Inhibition of 
Table VIII. Mean and median survival time.

\begin{tabular}{|c|c|c|}
\hline Variable & $\begin{array}{l}\text { Median survival } \\
\text { time (month) }\end{array}$ & $\begin{array}{l}\text { Mean surviva } \\
\text { time (month) }\end{array}$ \\
\hline \multicolumn{3}{|l|}{ EGFR } \\
\hline Low expression & - & 127.31 \\
\hline High expression & 58.00 & 63.91 \\
\hline \multicolumn{3}{|l|}{ Cyclin D1 } \\
\hline Low expression & - & 120.18 \\
\hline High expression & 29.00 & 66.58 \\
\hline \multicolumn{3}{|l|}{ KRAS } \\
\hline Low expression & - & 112.45 \\
\hline High expression & 32.00 & 57.23 \\
\hline \multicolumn{3}{|c|}{ Recurrence or metastasis } \\
\hline No & - & 143.04 \\
\hline Yes & 16.00 & 20.39 \\
\hline \multicolumn{3}{|l|}{ Clinical stage } \\
\hline I-II & - & 126.16 \\
\hline III & 37.00 & 83.59 \\
\hline IV & 9.00 & 8.00 \\
\hline \multicolumn{3}{|l|}{ Age } \\
\hline$<50$ & - & 96.33 \\
\hline$\geq 50$ & - & 92.62 \\
\hline \multicolumn{3}{|l|}{ Smoking } \\
\hline No & - & 88.32 \\
\hline Yes & - & 98.21 \\
\hline \multicolumn{3}{|l|}{ Drinking } \\
\hline No & - & 99.42 \\
\hline Yes & - & 86.05 \\
\hline
\end{tabular}

EGFR, epidermal growth factor receptor; KRAS, KRAS proto-oncogene, GTPase.

Table IX. Univariate analysis results for prognosis of patients with laryngocarcinoma using the Kaplan-Meier method.

\begin{tabular}{lrr}
\hline Variables & \multicolumn{1}{c}{$\chi^{2}$} & P-value \\
\hline EGFR & 4.261 & 0.039 \\
Cyclin D1 & 6.219 & 0.013 \\
KRAS & 5.916 & 0.015 \\
Recurrence or metastasis & 53.047 & $<0.001$ \\
Clinical stage & 45.233 & $<0.001$ \\
Age & 0.166 & 0.684 \\
Smoking & 0.168 & 0.682 \\
Drinking & 0.212 & 0.645 \\
\hline
\end{tabular}

EGFR, epidermal growth factor receptor; KRAS, KRAS proto-oncogene, GTPase.

EGFR can limit the growth of laryngeal squamous cell carcinoma and enhance the anticancer effect when combined with other drugs (16-18). The results of the current study indicated that EGFR expression in laryngocarcinoma was significantly increased compared with the vocal cord polyp tissues. In addition, increased EGFR expression was identified in tissues with higher TNM stage. High expression rates of EGFR were identified in 57.9, 77.3 and $100 \%$ of stage I-II, stage III and stage IV tissues, respectively. Furthermore, the EGFR expression rates were significantly different between different TNM stages, indicating that the expression of this protein may be closely associated with the occurrence, development, malignant transformation and proliferation of laryngocatcinoma. In addition, the results the current study indicated that EGFR expression was increased among patients with recurrence or metastasis following treatment of laryngocarcinoma compared with patients without recurrence or metastasis (expression rate, 88.9 vs. $60.7 \%$, respectively) suggesting that EGFR expression may promote laryngocarcinoma cell invasion and metastasis.

Cyclin D1 interacts with cyclin-dependent kinase (CDK)4 or CDK6 to induce cell cycle progression from the G1 to $\mathrm{S}$ phase and promote cell division or transformation (19). Aberrant expression of cyclin D1 may result in the imbalance of the cell cycle, resulting in tumorigenesis (20). Previous studies have confirmed that cyclin D1 is closely associated with the evolution of malignant tumors $(21,22)$. Overexpression of cyclin D1 is considered to be of clinical relevance in LSCC (23). Downregulation of cyclin D1 can inhibit cell growth and induce apoptosis in LSCC (24). In vivo studies using an LSCC xenograft model indicated that tumor growth can be inhibited by cyclin D1 downregulation $(25,26)$. In the present study, the expression levels of cyclin D1 were significantly different in laryngocarcinoma tissues compared with the vocal cord polyp tissues. Furthermore, higher TNM stages were associated with increased cyclin D1 expression. The expression rates in tissues with different TNM stages were 26.3, 68.2 and 80.0\%, respectively. Furthermore, the cyclin D1 expression rates were significantly different between different TNM stages, indicating that the expression of this protein may be closely associated with the malignant transformation of laryngeal tissues and tumor progression. The expression of cyclin D1 was increased among patients with recurrence or metastasis following treatment of laryngocarcinoma compared with patients without recurrence or metastasis (expression rate, 60.0 vs. $29.2 \%$, respectively) suggesting that cyclin D1 expression may serve a role in laryngocarcinoma invasion and metastasis.

KRAS is a proto-oncogene mediating oncogenic transformation via the MAPK signaling pathway dependent on the activation of Raf serine/threonine specific kinase $(27,28)$. A number of previous studies demonstrated that the KRAS gene served a role in the occurrence and development of various tumors $(29,30)$. The majority of studies have focused on the expression of KRAS in other tissues, including anal (31), oral (32), tonsil (33), skin (34) and head and neck squamous cell carcinoma (35). Although KRAS mutation has been reported in LSCC tissues and cell lines $(36,37)$, there is not sufficient evidence of the role of KRAS in LSCC. The current research indicated that KRAS expression in laryngocarcinoma tissue was significantly higher compared with the vocal cord tissue, and higher TNM stages were associated with increased KRAS expression. The high expression rates of tissues with different TNM stages were 15.8, 
Table X. Multivariate analysis results for prognosis of patients with laryngocarcinoma using the Cox regression model.

\begin{tabular}{|c|c|c|c|c|c|c|c|c|}
\hline \multirow[b]{2}{*}{ Variable } & \multirow[b]{2}{*}{ B } & \multirow[b]{2}{*}{ SE } & \multirow[b]{2}{*}{ Wald } & \multirow[b]{2}{*}{ df } & \multirow[b]{2}{*}{ P-value } & \multirow[b]{2}{*}{$\operatorname{Exp}(B)$} & \multicolumn{2}{|c|}{$95.0 \%$ CI for $\operatorname{Exp}(B)$} \\
\hline & & & & & & & Lower & Upper \\
\hline EGFR & -1.424 & 1.116 & 1.628 & 1 & 0.202 & 0.241 & 0.027 & 2.145 \\
\hline Cyclin D1 & -0.177 & 0.829 & 0.045 & 1 & 0.831 & 0.838 & 0.165 & 4.254 \\
\hline KRAS & -0.502 & 0.588 & 0.731 & 1 & 0.393 & 0.605 & 0.191 & 1.914 \\
\hline Recurrence or metastasis & 6.490 & 1.777 & 13.348 & 1 & 0.000 & 658.792 & 20.257 & $21,424.605$ \\
\hline Clinical stage I-II & - & - & 14.152 & 2 & 0.001 & 1 & - & - \\
\hline Clinical stage III & 2.774 & 1.157 & 5.746 & 1 & 0.017 & 16.025 & 1.658 & 154.848 \\
\hline Clinical stage IV & 5.078 & 1.389 & 13.355 & 1 & 0.000 & 160.439 & 10.533 & $2,443.721$ \\
\hline Age & -1.383 & 1.007 & 1.885 & 1 & 0.170 & 0.251 & 0.035 & 1.806 \\
\hline Smoking & 0.308 & 0.659 & 0.218 & 1 & 0.640 & 1.361 & 0.374 & 4.950 \\
\hline Drinking & -0.684 & 0.639 & 1.147 & 1 & 0.284 & 0.505 & 0.144 & 1.765 \\
\hline
\end{tabular}

EGFR, epidermal growth factor receptor; KRAS, KRAS proto-oncogene, GTPase; df, degrees of freedom; CI, confidence interval; B, regression coefficient; SE, standard error; Wald, a statistic to test B value; $\operatorname{Exp}(\mathrm{B})$, the exponent of B.
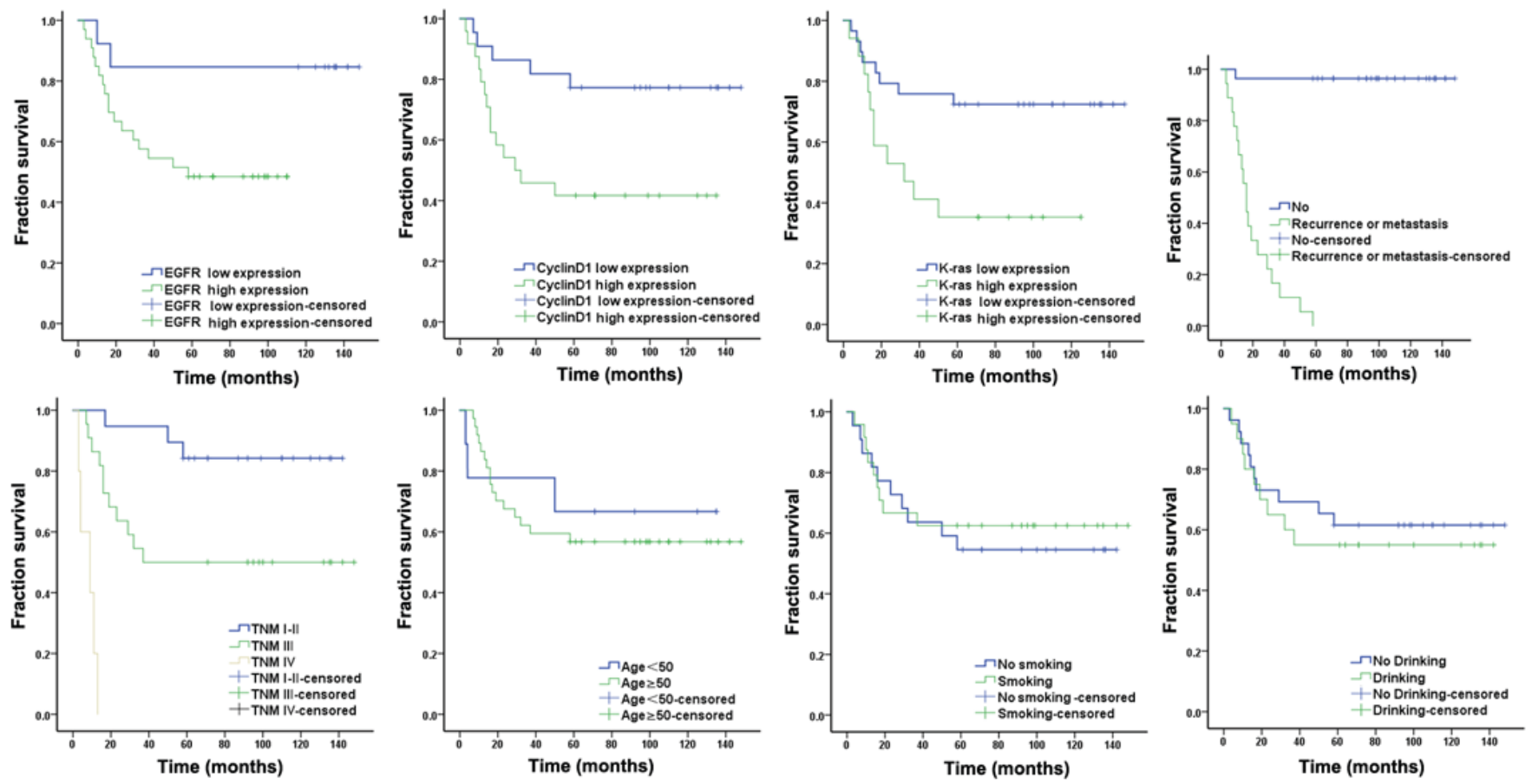

Figure 2. Kaplan-Meier survival curves for patients with different EGFR, cyclin D1 and KRAS expression levels, metastasis and recurrence status, clinical stage, age, and smoking and drinking status. EGFR, epidermal growth factor receptor; KRAS, KRAS proto-oncogene, GTPase.

50.0 and $80.0 \%$, respectively. Furthermore, the KRAS expression rates were significantly different between different TNM stages, indicating that the expression of this protein may be closely associated with to the occurrence and development of laryngocarcinoma. KRAS expression in tissues from patients with recurrence or metastasis after laryngocarcinoma treatment was significantly higher compared with patients without recurrence or metastasis (expression rate, 60.0 vs. 20.8\%), suggesting that KRAS expression may serve an important role in laryngocarcinoma invasion and metastasis.

The current study indicated that the expression levels of EGFR, cyclin D1 and KRAS are closely associated with the clinical stage of laryngocarcinoma and recurrence or metastasis status after treatment. In addition, previous studies indicated that EGFR, cyclin D1 and KRAS expression levels were associated with the occurrence and development of laryngocarcinoma, with high expression levels promoting invasion and metastasis of laryngocarcinoma cells (37-39).

The results of the current study indicated that the expression levels of EGFR, cyclin D1 and KRAS in laryngocarcinoma tissues increased compared with vocal cord polyp tissues tissues and were closely associated with the clinical stage and tumor recurrence or metastasis after treatment. There was a positive correlation between the expression levels 
of any two of these factors in laryngocarcinoma, indicating that these genes may act in synergy to promote the occurrence and development of laryngocarcinoma. The following mechanism underlying such synergy may be hypothesized: Activation of EGFR by ligand binding may active the Ras/Raf pathway and induce the expression and activation of cyclin D1 through the MAPK pathway to promote cell cycle progression into $\mathrm{S}$ phase and initiate proliferation. Previous studies have indicated that there was no significant correlation among EGFR, cyclin D1 and KRAS expression in laryngocarcinoma $(40,41)$. The reason may be that EGFR, cyclin D1 and KRAS is only a part of numerous complex cellular signaling pathways involved in the process of carcinogenesis, and may have different expression stages in these signaling pathways during the initiation and progression of laryngocarcinoma $(40,42)$.

In the present study, the Kaplan-Meier method was used to calculate the mean survival time and survival rate of patients in each group. The results indicated that there was a significant difference in survival rate between the EGFR, cyclin D1 and KRAS low and high expression groups. The Kaplan-Meier survival curves indicated that the survival rates of patients in the EGFR, cyclin D1 and KRAS high expression groups were significantly lower compared with patients in the low expression groups. Therefore, the expression of EGFR, cyclin D1 and KRAS may be associated with the survival rate of patients with laryngocarcinoma and is one of the factors affecting the survival and prognosis.

Multivariate analysis of prognosis using the Cox regression model indicated that the clinical stage of laryngocarcinoma and treatment response were closely associated with the prognosis of patients. There were significant differences in survival rates between patients with different TNM stages, which suggested that the clinical stage of laryngocarcinoma and treatment response are independent risk factors for the prognosis of patients, whereas age, smoking, drinking states and expression of EGFR, cyclin D1 and KRAS were the relative risk factors and may influence the prognosis in the presence of other factors.

The major limitation of the current study was that the male/female ratio was $45: 1$, which is higher than that in previously reported studies, although LSCC is more prevalent among males (43). This limitation is due to the relatively low case number and recruitment of patients from a single hospital. Future studies should include patients from multiple hospitals.

In conclusion, the current study indicated that the expression levels of EGFR, cyclin D1 and KRAS were closely associated with the clinical stage of patients and may serve roles in the recurrence or metastasis after treatment. Therefore, aberrant expression of these three genes may accelerate the growth and invasion of laryngocarcinoma cells and promote recurrence or metastasis, thus influencing the prognosis of patients. Clinically, patient prognosis may be assessed by detecting the expression of EGFR, cyclin D1 and KRAS genes, especially EGFR, which could serve as a novel marker for LSCC. Surgery combined with radiotherapy and/or chemotherapy, which can be adopted for high-expression and high-stage patients, combined with specific targeted EGFR, cyclin D1 or KRAS gene recombination therapy may reduce the residual tumor size, prevent recurrence or metastasis and improve the prognosis of patients.

\section{Acknowledgements}

Not applicable.

\section{Funding}

The present study was supported by the Shantou Science and Technology Planning Project (grant no. Shanfuke 2011-46-4).

\section{Availability of data and materials}

The datasets used and/or analyzed during the current study are available from the corresponding author on reasonable request.

\section{Authors' contributions}

XL collected the samples and analyzed the data. GW and SW performed immunohistochemical assays and evaluated the results. HL and CL performed statistical analysis. XW designed the present study and was the major contributor to the writing of this manuscript. All authors read and approved the final version of this manuscript.

\section{Ethics approval and consent to participate}

The present study was conducted in accordance with the Declaration of Helsinki and was approved by the Ethics Committee of Shantou Central Hospital (Shantou, China). Written informed consent was obtained from all participants.

\section{Patient consent for publication}

Written informed consent was obtained from all participants.

\section{Competing interests}

The authors declare that they have no competing interests.

\section{References}

1. Zhi L, Wenli W, Pengfei G, Pengcheng C, Wenxian C, Jiasheng L and Yongzhu S: Laryngotracheal reconstruction with autogenous rib cartilage graft for complex laryngotracheal stenosis and/or anterior neck defect. Eur Arch Otorhinolaryngol 271: 317-322, 2014.

2. Britt CJ and Gourin CG: Contemporary management of advanced laryngeal cancer. Laryngoscope Investig Otolaryngol 2: 307-309, 2017.

3. Alterio D, Marvaso G, Maffini F, Gandini S, Chiocca S, Ferrari A, Preda L, Rocca MC, Lepanto D, Fodor C, et al: Role of EGFR as prognostic factor in head and neck cancer patients treated with surgery and postoperative radiotherapy: Proposal of a new approach behind the EGFR overexpression. Med Oncol 34: 107, 2017.

4. Cho KJ, Jeong SU, Kim SB, Lee SW Choi SH, Nam SY and Kim SY: Basaloid squamous cell carcinoma of the head and neck: Subclassification into basal, ductal and mixed subtypes based on comparison of clinico-pathologic features and expression of p53, Cyclin D1, epidermal growth factor receptor, p16 and human papillomavirus. J Pathol Transl Med 51: 374-380, 2017. 
5. Paliga A, Onerheim R, Gologan A, Chong G, Spatz A, Niazi T, Garant A, Macheto D, Alcindor T and Vuong T: EGFR and K-ras gene mutation status in squamous cell anal carcinoma: A role for concurrent radiation and EGFR inhibitors? Br J Cancer 107: $1864-1868,2012$

6. Bellacosa A, Almadori G, Cavallo S, Cadoni G, Galli J, Ferrandina G, Scambia G and Neri G: Cyclin D1 gene amplification in human laryngeal squamous cell carcinomas: Prognostic significance and clinical implications. Clin Cancer Res 2: 175-180, 1996.

7. Trivedi S, Rosen CA and Ferris RL: Current understanding of the tumor microenvironment of laryngeal dysplasia and progression to invasive cancer. Curr Opin Otolaryngol Head Neck Surg 24 121-127, 2016

8. Takes RP, Baatenburg de Jong RJ, Schuuring E, Hermans J, Vis AA, Litvinov SV and van Krieken JH: Markers for assessment of nodal metastasis in laryngeal carcinoma. Arch Otolaryngo Head Neck Surg 123: 412-419, 1997.

9. Shin DM, Ro JY, Hong WK and Hittelman WN: Dysregulation of epidermal growth factor receptor expression in premalignant lesions during head and neck tumorigenesis. Cancer Res 54 3153-3159, 1994.

10. Horn F, Henze $\mathrm{C}$ and Heidrich $\mathrm{K}$ : Interleukin-6 signal transduction and lymphocyte function. Immunobiology 202: 151-167, 2000.

11. Gospodarowicz MK, Brierley JD and Wittekind C: TNM classification of malignant tumours. John Wiley \& Sons, 2017.

12. Sigismund S, Avanzato D and Lanzetti L: Emerging functions of the EGFR in cancer. Mol Oncol 12: 3-20, 2018.

13. Tetsu O, Phuchareon J, Eisele DW, Hangauer MJ and McCormick F: AKT inactivation causes persistent drug tolerance to EGFR inhibitors. Pharmacol Res 102: 132-137, 2015.

14. Moeini A, Sia D, Bardeesy N, Mazzaferro V and Llovet JM: Molecular pathogenesis and targeted therapies for intrahepatic cholangiocarcinoma. Clin Cancer Res 22: 291-300, 2016

15. Zhang S, Li Y, He X, Dong S, Huang Y, Li X, Li Y, Jin C Zhang $\mathrm{Y}$ and Wang Y: Photothermolysis mediated by gold nanorods modified with EGFR monoclonal antibody induces Hep-2 cells apoptosis in vitro and in vivo. Int J Nanomedicine 9: 1931-1946, 2014

16. Cao S, Xia M, Mao Y, Zhang Q, Donkor PO, Qiu F and Kang N: Combined oridonin with cetuximab treatment shows synergistic anticancer effects on laryngeal squamous cell carcinoma: Involvement of inhibition of EGFR and activation of reactive oxygen species-mediated JNK pathway. Int J Oncol 49: 2075-2087, 2016

17. Kang N, Zhang JH, Qiu F, Tashiro S, Onodera S and Ikejima T: Inhibition of EGFR signaling augments oridonin-induced apoptosis in human laryngeal cancer cells via enhancing oxidative stress coincident with activation of both the intrinsic and extrinsic apoptotic pathways. Cancer Lett 294: 147-158, 2010.

18. Hwang H, Biswas R, Chung PS and Ahn JC: Modulation of EGFR and ROS induced cytochrome c release by combination of photodynamic therapy and carboplatin in human cultured head and neck cancer cells and tumor xenograft in nude mice. J Photochem Photobiol B 128: 70-77, 2013

19. Gioacchini FM, Alicandri-Ciufelli M, Kaleci S, Magliulo G, Presutti L and Re M: The prognostic value of cyclin D1 expression in head and neck squamous cell carcinoma. Eur Arch Otorhinolaryngol 273: 801-809, 2016

20. Pletneva MA, Andea A, Palanisamy N, Betz BL, Carskadon S, Wang M, Patel RM, Fullen DR and Harms PW: Clear cell melanoma: A cutaneous clear cell malignancy. Arch Pathol Lab Med 138: 1328-1336, 2014

21. Qie S and Diehl JA: Cyclin D1, cancer progression, and opportunities in cancer treatment. J Mol Med (Berl) 94: 1313-1326, 2016.

22. Casimiro MC, Velasco-Velazquez M, Aguirre-Alvarado C and Pestell RG: Overview of cyclins D1 function in cancer and the CDK inhibitor landscape: Past and present. Expert Opin Investig Drugs 23: 295-304, 2014

23. Pignataro L, Pruneri G, Carboni N, Capaccio P, Cesana BM, Neri A and Buffa R: Clinical relevance of cyclin D1 protein overexpression in laryngeal squamous cell carcinoma. J Clin Oncol 16: 3069-3077, 1998

24. Xiao Y, Wang J, Lu J, Liu Y, Wang Y, Gao Y and Jin D: Down-regulation of cyclin D1 by small interfering RNA inhibits cell growth and induces apoptosis of laryngeal squamous cell carcinoma. Am J Otolaryngol 32: 541-546, 2011.
25. Feng J, Sun Q, Wu T, Lu J, Qu L, Sun Y, Tian L, Zhang B, Li D and Liu M: Upregulation of ATF-3 is correlated with prognosis and proliferation of laryngeal cancer by regulating Cyclin D1 expression. Int J Clin Exp Pathol 6: 2064-2070, 2013.

26. Li MH, Tian LL, Ren H, Chen XX, Wang Y, Ge JC, Wu SL, Sun Y, Liu M and Xiao H: MicroRNA-101 is a potential prognostic indicator of laryngeal squamous cell carcinoma and modulates CDK8. J Transl Med 13: 271, 2015.

27. Akkiprik M, Celikel CA, Düşünceli F, Sönmez O, Güllüoğlu BM, Sav A and Ozer A: Relationship between overexpression of ras p21 oncoprotein and K-ras codon 12 and 13 mutations in Turkish colorectal cancer patients. Turk J Gastroenterol 19: 22-27, 2008.

28. Haigis KM, Kendall KR, Wang Y, Cheung A, Haigis MC, Glickman JN, Niwa-Kawakita M, Sweet-Cordero A, Sebolt-Leopold J, Shannon KM, et al: Differential effects of oncogenic K-Ras and N-Ras on proliferation, differentiation and tumor progression in the colon. Nat Genet 40: 600-608, 2008.

29. Nussinov R, Tsai CJ and Jang H: A new view of pathway-driven drug resistance in tumor proliferation. Trends Pharmacol Sci 38: 427-437, 2017.

30. Asati V, Mahapatra DK and Bharti SK: K-Ras and its inhibitors towards personalized cancer treatment: Pharmacological and structural perspectives. Eur J Med Chem 125: 299-314, 2017.

31. Zampino MG, Magni E, Sonzogni A and Renne G: K-ras status in squamous cell anal carcinoma (SCC): It's time for target-oriented treatment? Cancer Chemother Pharmacol 65: 197-199, 2009.

32. Shin KH, Bae SD, Hong HS, Kim RH, Kang MK and Park NH miR-181a shows tumor suppressive effect against oral squamous cell carcinoma cells by downregulating K-ras. Biochem Biophys Res Commun 404: 896-902, 2011.

33. Van Damme N, Deron P, Van Roy N, Demetter P, Bols A, Van Dorpe J, Baert F, Van Laethem JL, Speleman F, Pauwels P and Peeters M: Epidermal growth factor receptor and K-RAS status in two cohorts of squamous cell carcinomas. BMC Cancer 10: 189, 2010.

34. van der Schroeff JG, Evers LM, Boot AJ and Bos JL: Ras oncogene mutations in basal cell carcinomas and squamous cell carcinomas of human skin. J Invest Dermatol 94: 423-425, 1990.

35. Hoa M, Davis SL, Ames SJ and Spanjaard RA: Amplification of wild-type K-ras promotes growth of head and neck squamous cell carcinoma. Cancer Res 62: 7154-7156, 2002

36. Chen X, Kong W, Cai G, Zhang S and Zhang D: The expressions of K-ras in human laryngeal squamous cell carcinoma cell lines (Hep-2) and its significance. Lin Chuang Er Bi Yan Hou Ke Za Zhi 19: 417-419, 2005 (In Chinese).

37. Ruíz-Godoy R LM, Garcia-Cuellar CM, Herrera González NE, Suchil BL, Pérez-Cárdenas E, Sácnchez-Pérez Y, Suárez-Roa ML and Meneses A: Mutational analysis of K-ras and Ras protein expression in larynx squamous cell carcinoma. J Exp Clin Cancer Res 25: 73-78, 2006.

38. Shang C, Guo Y, Fu S, Fu W and Sun K: SH3GL2 gene participates in MEK-ERK signal pathway partly by regulating EGFR in the laryngeal carcinoma cell line Hep2. Med Sci Monit 16: BR168-BR173, 2010

39. Zhang B, Liu W, Li L, Lu J, Liu M, Sun Y and Jin D: KAI1/CD82 and CyclinD1 as biomarkers of invasion, metastasis and prognosis of laryngeal squamous cell carcinoma. Int J Clin Exp Pathol 6: 1060-1067, 2013.

40. Chrysovergis A, Gorgoulis VG, Giotakis I, Tsiambas E, Karameris A, Kittas C and Kyroudi A: Simultaneous over activation of EGFR, telomerase (h TERT) and cyclin D1 correlates with advanced disease in larynx squamous cell carcinoma: A tissue microarray analysis. Med Oncol 28: 871-877, 2011.

41. Ramnani DM, Wistuba II, Behrens C, Gazdar AF, Sobin LH and Albores-Saavedra J: K-ras and p53 mutations in the pathogenesis of classical and goblet cell carcinoids of the appendix. Cancer 86 : 14-21, 1999

42. Papadimitrakopoulou V, Izzo JG, Liu DD, Myers J, Ceron TL, Lewin J, William WN Jr, Atwell A, Lee JJ, Gillenwater A, et al: Cyclin D1 and cancer development in laryngeal premalignancy patients. Cancer Prev Res (Phila) 2: 14-21, 2009.

43. Ferlay J, Soerjomataram I, Dikshit R, Eser S, Mathers C, Rebelo M, Parkin DM, Forman D and Bray F: Cancer incidence and mortality worldwide: Sources, methods and major patterns in GLOBOCAN 2012. Int J Cancer 136: E359-E386, 2015.

This work is licensed under a Creative Commons

Attribution-NonCommercial-NoDerivatives 4.0 International (CC BY-NC-ND 4.0) License. 